\title{
A method for simplifying the analysis of traffic accidents injury severity on two-lane highways using Bayesian networks
}

\author{
By: Randa O. Mujalli and Juan de Oña \\ This document is a post-print versión (ie final draft post-refereeing) of the following \\ paper: \\ Randa O. Mujalli and Juan de Oña (2011) A method for simplifying the analysis of \\ traffic accidents injury severity on two-lane highways using Bayesian networks. Journal \\ of Safety Research, 42, 317-326. \\ Direct access to the published version: http://dx.doi.org/10.1016/j.jsr.2011.06.010
}




\section{A method for simplifying the analysis of traffic accidents injury severity on two-lane highways using Bayesian networks}

Randa Oqab Mujalli and Juan de Oña ${ }^{\#}$

TRYSE Research Group. Department of Civil Engineering, University of Granada

\# Corresponding author, ETSI Caminos, Canales y Puertos, c/ Severo Ochoa, s/n, 18071 Granada (Spain),

Phone: +349582499 79, email: jdona@ugr.es 
- It is possible to reduce the number of variables in the analysis of traffic accidents

- A selected subset of variables can improve the performance of traffic accidents models

- Seven variables were found to be the most significant in traffic accidents injury severity 


\title{
A method for simplifying the analysis of traffic accidents injury severity on two-lane highways using Bayesian networks
}

\begin{abstract}
Introduction: This study describes a method for reducing the number of variables frequently considered in modeling the severity of traffic accidents. The method's efficiency is assessed by constructing Bayesian networks (BN). Method: It is based on a two stage selection process. Several variable selection algorithms, commonly used in data mining, are applied in order to select subsets of variables. BNs are built using the selected subsets and their performance is compared with the original BN (with all the variables) using five indicators. The BNs that improve the indicators' values are further analyzed for identifying the most significant variables (accident type, age, atmospheric factors, gender, lighting, number of injured and occupant involved). A new BN is built using these variables, where the results of the indicators indicate in most of the cases, a statistically significant improvement with respect to the original $\mathrm{BN}$. Conclusions: It is possible to reduce the number of variables used to model traffic accidents injury severity through BNs without reducing the performance of the model. Impact on Industry: The study provides the safety analysts a methodology that could be used to minimize the number of variables used in order to determine efficiently the injury severity of traffic accidents without reducing the performance of the model.
\end{abstract}

Keywords: injury severity, variable selection, Bayesian networks, data mining, classification

\section{Introduction}

A lot of information on traffic accidents exists, extracted from different sources, in which many variables that are expected to affect injury severity in traffic accidents are considered. The number of variables used in research work could be enormous, and in some cases this number could be even higher than 100 variables (Delen et. al., 2006). This might complicate the manner of dealing with a certain problem, where some of the variables considered might hide the effect of other more significant ones. A lot of different types of studies tried to identify the most significant variables in order to only consider them in the analysis of traffic accidents (Xie et al., 2009; Kopelias et al., 2007; Chang and Wang, 2006; Chen and Jovanis, 2000). Therefore, researchers in the field of traffic accidents and specifically in the domain of traffic accident injury severity focused their research on trying to identify the most significant variables that contribute to the occurrence of a specific injury severity in a traffic accident.

Most previous research utilized regression analysis techniques, such as logistic and ordered probit models (Al-Ghamdi, 2002; Milton et al. 2008; Bédard et al. 2002; Yau et al., 2006; Yamamoto and Shankar, 2004; Kockelman and Kweon, 2002). These techniques have their own drawbacks. Chang and Wang (2006) indicated that these regression models use certain assumptions, and if any of these assumptions were violated, the ability of the model to predict the factors that contribute to the occurrence of a specific injury severity would be affected.

Recently researchers used data mining techniques, such as artificial neural networks, regression trees and Bayesian networks.

For instance, Abdelwahab and Abdel-Aty (2001) used artificial neural networks to model the relationship between driver injury severity and crash factors related to driver, vehicle, roadway, and environment characteristics. Thirteen variables were tested first for significance using the $\chi^{2}$ test, and the results indicated that only six variables were found to be significant: driver gender, fault, vehicle type, seat belt, point of impact, and area type. They compared the classification performance of MultiLayer Perceptron (MLP) neural networks and that of the Ordered Probit Model (OPM). Their findings 
indicated that classification accuracy of MLP neural networks outperformed that of the OPM, where $65.6 \%$ and $60.4 \%$ of cases were correctly classified for the training and testing phases, respectively, compared to $58.9 \%$ and $57.1 \%$ correctly classified cases for the training and testing phases, respectively, by the OPM.

Another study that used the neural networks to model injury severity in traffic accidents (Delen et. al., 2006) classified the injury severity of a traffic accident into five categories (no injury, possible injury, minor non-incapacitating injury, incapacitating and fatality) and they used certain techniques, such as $\chi^{2}$ test, stepwise logistic regression and decision tree induction to select the most significant variables. Out of 150 variables, they selected 17 variables as important in influencing the level of injury severity of drivers involved in accidents. They used the MLP neural networks to classify the injury severity level, where their data included "no injury" cases 10 times more than "fatal cases"; they faced an unbalanced dataset situation which affected their total accuracy (40.71\%).

Other researchers used classification tree techniques to model injury severity in traffic accidents (Chang and Wang, 2006). In their study they developed a Classification and Regression Tree (CART) model to establish the relationship between injury severity and twenty explanatory variables that represented: driver/vehicle characteristics, highway/environmental variables and accident variables, where they aimed to model the injury severity of an individual involved in a traffic accident.

Use of Bayesian Networks (BN) as the modeling approach in analysis of crash-related injury severity has been relatively scarce. De Oña et al. (2011) employed BN to model the relationship between injury severity and 18 variables related to driver, vehicle, roadway, and environment characteristics.

Some of these studies tend to apply the models on the datasets without selecting the most significant variables (Delen et. al., 2006; Chang and Wang 2006; Simoncic, 2004). However, Chang and Wang (2006) stated that if the model was applied on a few important variables, much more useful results could be obtained. Others like Abdelwahab and Abdel-Aty (2001) used some statistical techniques to choose the most significant variables before applying their model.

The scope of this research is to build BNs using some selected variables in order to evaluate the performance of BNs when using only the most significant variables, and to compare the results with a base model that is built using all the variables in the original dataset, in order to find out whether using only the most significant variables would affect values of the measures used to assess the built model.

This paper is organized as follows. Section 2 presents the data used. In section 3, the method followed is presented and described, and a brief review of variable selection methods and the basic concept of BNs are presented, along with a description of the performance indicators used to assess the performance of the built BNs. In section 4, the results and their discussion are provided. In section 5, some conclusions are given.

\section{Accident data}

Accident data were obtained from the Spanish General Traffic Directorate (DGT) for rural highways in the province of Granada (southern Spain) for three years (2003-2005). The total number of accidents obtained for this period was 3,302. The data was first checked out for questionable data, and those which were found to be unrealistic were screened out. Only rural highways were considered in this study; data related to intersections were not included, since intersections have their own specific characteristics and need to be analyzed separately. Finally, the database used to conduct the study contained 1,536 records. Table 1 provides information on the data used for this study.

(insert Table 1) 
Eighteen (18) variables were used with the class variable of injury severity (SEV) in an attempt to identify the important variables that affect injury severity in traffic accidents.

The data contained information related to the accidents and other information related to the drivers.

The data included variables describing the conditions that contributed to the accident and injury severity.

- Injury severity variables: number of injuries (e.g., passengers, drivers and pedestrians), severity level of injuries (e.g., slight injured -SI- and killed or seriously injured -KSI). Following previous studies (Chang and Wang, 2006; Milton et al., 2008) the injury severity of an accident is determined according to the level of injury to the worst injured occupant.

- Roadway information: characteristics of the roadway on which the accidents occurred (e.g., pavement width, lane width, shoulder type, pavement markings, sight distance, if the shoulder was paved or not, etc.)

- Weather information: weather conditions when the accident occurred (e.g., good weather, rain, fog, snow and windy)

- Accident information: contributing circumstances (e.g., type of accident, time of accident (hour, day, month and year), and vehicles involved in the accident).

- Driver data: characteristics of the driver, such as age or gender

\section{Method}

The procedure used in this study has been the following:

1. The original dataset obtained from the DGT was divided into two subsets: a training set containing $2 / 3$ of the data (1,024 records), and a testing set containing the rest of the data (512 records). The testing set was used to validate the results obtained using the training set.

2. Based on the eighteen variables taken from the accident reports (see Table 1), identification of the variables that affect injury severity in traffic accidents was performed using different methods of evaluator-search algorithms.

3. For each one of the selected subsets of variables, ten simplified BNs were built using the hill climbing search algorithm and the MDL score (De Oña et al., 2011).

4. The performance of the built BNs using the selected subsets of variables was compared with the performance of the original $\mathrm{BN}$ which was built using the eighteen variables $(\mathrm{BN}-18)$. Five performance evaluation indicators were used.

5. Of all the simplified built BNs, the selected ones are those whose results improve or maintain the results obtained by the performance indicators of $\mathrm{BN}-18$ in $90 \%$ of the cases or more, and whose improvements are statistically significant.

6. For the selected BNs, the variables that repeat in more than $50 \%$ of the cases are identified and a new BN is built using these variables.

7. Finally, the results obtained by this new $\mathrm{BN}$, based on a double process of variable selection procedure, are compared with those obtained by $\mathrm{BN}-18$.

\subsection{Variable selection methods}

In machine learning, variable selection is a process that is used to select a subset of variables and to remove variables that do not contribute to the performance of the machine learning technique used. 
In this study, we used six evaluators with eleven search methods. Weka's Select Variable Panel (Witten and Frank, 2005) was used to perform the variable selection.

A brief description of each of the evaluators used is given below:

1. Correlation-based variable selection (CfsSubsetEval): this evaluator measures the predictive ability of each variable individually and the degree of redundancy among them. It selects the sets of variables that are highly correlated with the class but have low inter-correlation with each other (Hall, 1998).

2. Consistency-based variable selection (ConsistencySubsetEval): this evaluator measures the degree of consistency of the variable sets in class values when the training values are projected onto the set. This evaluator is usually used in conjunction with a random or exhaustive search (Liu and Setiono, 1996).

3. Classifier Subset Evaluator (ClassifierSubsetEval): this evaluator uses the classifier specified in the object editor as a parameter, to evaluate sets of variables on the training data or on a separate holdout set (Witten and Frank, 2005).

4. Wrapper Subset Evaluator (WrapperSubsetEval): this evaluator uses a classifier to evaluate variable sets and it employs cross-validation to estimate the accuracy of the learning scheme for each set (Khhavi and John, 1997).

5. Filtered Subset Evaluator (FilteredSubsetEval): The filter model evaluates the subset of variables by examining the intrinsic characteristic of the data without involving any data mining algorithm (Witten and Frank, 2005).

6. Cost Sensitive Subset Evaluator (CostSensitiveSubsetEval): This evaluator projects the training set into attribute set and measure consistency in class values, making the subset cost sensitive (Liu and Setiono, 1996).

A brief description of each of the search methods used is given below:

1. Best First: this Search method uses greedy hillclimbing augmented with a backtracking facility to search through the variables' subsets. Best first may start with an empty set of variables and search forward, or start with a full set of variables and search backward, or start at any point and search in both directions (Pearl, 1984).

2. Genetic Search: An initial population is formed by generating many individual solutions. During each successive generation, a proportion of the existing population is selected to breed a new generation. This process is repeated until increasing the average fitness, and reaching a termination condition (Goldberg, 1989).

3. Greedy Stepwise: Performs a greedy forward or backward search through the space of variables' subsets. The search could be initiated with none or with all the variables or from an arbitrary point in the space. Thus, the search is stopped when the addition or deletion of any variables that remains; results in a decrease in evaluation (Russell and Norvig, 2003).

4. Linear Forward Selection: this search method is an extension of Best First where a fixed number $\mathrm{k}$ of variables is selected, whereas $\mathrm{k}$ is increased in each step when fixed-width is selected. The search direction can be forward or floating forward selection (with optional backward search steps) (Gutlein et al., 2009).

5. Scatter Search V1: Starts with a population of many significant variables and stops when the result is higher than a given threshold or when no further improvement could be attained (García López et al.,2006).

6. Tabu Search: It explores the solution space beyond the local optimum, once a local optimum is reached; upward moves and those worsening the solutions are allowed (Hedar, 2008). 
7. Rank Search: Uses a variable/subset evaluator to rank all variables. If a subset evaluator is specified then a forward selection search is used to generate a ranked list. From the ranked list of variables, subsets of increasing size are evaluated (Witten and Frank, 2005).

8. Exhaustive Search: Performs an exhaustive search through the space of variables' subsets starting from the empty set of variables and reporting the best subset found (Witten and Frank, 2005).

9. Subset Size Forward Selection: Performs an interior cross-validation, where it is performeded on each fold to determine the optimal subset-size. In the final step the search is performed on the whole data (Gutlein et al., 2009).

10. Random Search: Performs a random search in the space of variables' subsets. A random search is started from a random point, if no initial point is chosen, and reports the best subset found. If a start set is set, Random searches randomly for subsets that are as good as or better than the start point with the same number of variables or with a lower number of variables (Liu and Setiono, 1996).

11. Race Search: Races the cross validation error of competing subsets of variables, and is only used with a ClassifierSubsetEval (Moore and Lee,1994).

\subsection{Bayesian Networks definition}

Over the last decade, BNs have become a popular representation for encoding uncertain expert knowledge in expert systems. The field of BNs has grown enormously, with theoretical and computational developments in many areas (Mittal et al., 2007) such as: modeling knowledge in bioinformatics, medicine, document classification, information retrieval, image processing, data fusion, decision support systems, engineering, gaming, and law.

Let $U=\left\{x_{1}, \ldots, x_{n}\right\}, n \geq 1$ be a set of variables. A BN over a set of variables $U$ is a network structure, which is a Directed Acyclic Graph (DAG) over $U$ and a set of probability tables $B_{p}=\left\{p\left(x_{i} \mid p a\left(x_{i}\right), x_{i} \in\right.\right.$ $U)\}$ where $p a\left(x_{i}\right)$ is the set of parents or antecedents of $x_{i}$ in BN and $i=(1,2,3, \ldots, n)$. A BN represents joint probability distributions $P(U)=\prod_{x_{i} \in U} p\left(x_{i} \mid p a\left(x_{i}\right)\right)$.

Based on the theory of Bayesian networks (Neapolitan, 2004) the relations between variables, represented by arcs in the graph, could represent causality, relevance or relations of direct dependence between variables. In accordance with other authors (Acid et al., 2004), we do not assume a causal intrpretation of the arcs in the networks, although in some cases this might be reasonable (other approaches that explicitly try to detect causal influence are discussed in Glymour et al. (1999) and Pearl (2000)). Instead, the arcs are interpreted as direct dependence relationships between the linked variables, and the absence of arcs means the absence of direct dependence between variables, however indirect dependence relationships between variables could exist.

The classification task consists in classifying a variable $y=x_{0}$ called the class variable, given a set of variables $U=x_{1} \ldots x_{n}$, called attribute variables. A classifier $h: U \rightarrow y$ is a function that maps an instance of $U$ to a value of $y$. The classifier is learned from a dataset $\mathrm{D}$ consisting of samples over $(U$, y). The learning task consists of finding an appropriate $\mathrm{BN}$ given a data set $\mathrm{D}$ over $U$.

For each one of the variable subsets selected in the previous step, BNs were built using the training dataset, the hill climbing search algorithm and the MDL score. The search algorithm and the score were applied in this study mainly because they are fast and widely used, and also produce good results in terms of network complexity and accuracy (Madden, 2009).

\subsection{Performance Evaluation Indicators}


In order to measure the performance of the BNs built for each one of the variable subsets with the training data several indicators were used. The performance evaluation indicators used in this study were accuracy, specificity, sensitivity, the harmonic mean of sensitivity and specificity (HMSS) and the ROC area.

$$
\begin{aligned}
& \text { Accuracy }=\frac{\mathrm{tSI}+\mathrm{tKSI}}{\mathrm{tSI}+\mathrm{tKSI}+\mathrm{fSI}+\mathrm{fKSI}} 100 \% \\
& \text { Sensitivity }=\frac{\mathrm{tSI}}{\mathrm{tSI}+\mathrm{fKSI}} 100 \% \\
& \text { Specificity }=\frac{\mathrm{tKSI}}{\mathrm{tKSI}+\mathrm{fSI}} 100 \% \\
& \text { HMSS }=\frac{2 \times \text { sensitivity } \times \text { specificity }}{\text { sensitivity }+ \text { specificity }}
\end{aligned}
$$

Where $t S I$ is true slight injured cases, $t K S I$ true killed or seriously injured cases, $f S I$ false slight injured cases, and $f K S I$ false killed or seriously injured cases.

Accuracy (see Eq. 1) is proportion of instances that were correctly classified by the classifier. Accuracy only gives information on the classifier's general performance. In some cases the accuracy might be high because the classifier is able to classify values that belonged to only one class correctly. Because the dataset used herein had an imbalanced distribution of KSI and SI, the overall accuracy alone is somewhat misleading. In order to assess the performance of the classifier, other measures should be used along with the overall accuracy, such as the quantities presented in Eqs. (2-4).

Sensitivity represents the proportion of correctly predicted SI among all the observed SI. Specificity represents the proportion of correctly predicted KSI among all the observed KSI (see Eqs. 2 and 3). Another measure used to assess the performance of the BN built was the Harmonic Mean of Sensitivity and Specificity (HMSS), which gives an equal weight of both sensitivity and specificity (see Eq. 4).

However, there is a trade-off between sensitivity and specificity, meaning it is necessary to calculate another evaluation method. Therefore, we used the area under a Receiver Operating Characteristic (ROC) curve as a target performance method. What ROC curves represent is the true positive rate (sensitivity) vs. the false positive rate (1-specificity). ROC curves are more useful as descriptors of overall performance, reflected by the area under the curve, with a maximum of 1.00 describing a perfect test and an ROC area of 0.50 describing a valueless test.

Finally, to validate the results, the measures described above are also calculated for each $\mathrm{BN}$ and the testing dataset.

\section{Results and Discussion}

All the possible combinations of evaluator-search algorithms described in section 3.1 were applied (59 combinations). The total number of combinations was supposed to be 66 ; however, seven combinations were found to be incompatible. Table 2 shows the unused combinations.

\section{(insert table 2)}

Table 3 shows the variables selected after running the 59 different combinations of the evaluatorsearch algorithms. The number of selected variables lies between four variables (ACT, ATF, LIG and NOI), as obtained using Correlation-based variable selection, Filtered Subset Evaluator and Cost 
Sensitive Subset Evaluator with several search methods, and a maximum number of sixteen selected variables.

(insert table 3)

The same subset of variables could be selected by several evaluator-search combinations. As an example, one of the subset composed of four variables (ACT, ATF, LIG and NOI) is selected by seventeen different combinations of evaluator-search algorithms.

(insert table 4)

Table 4 shows the number of times that each one of the eighteen variables has been selected. There are three variables that were selected approximately 95\% of times. The variables ACT (accident type) and LIG (lighting) were selected 58 times over 59 combinations, which mean that they were selected almost by all the evaluator-search combinations. NOI (number of injuries) was the third most selected variable (56 times). The forth most selected variable was ATF (atmospheric factors) with 42 times. On the other hand, the least selected variable was ROM (pavement markings), with only 5 times.

For each subset of selected variables $20 \mathrm{BNs}$ were built representing 10 runs for the training set, and 10 for the testing set, for each one of the selected variable groups (26 groups) and for the eighteen original variables. In total, $540 \mathrm{BNs}$ have been built for this analysis. The averages of the performance evaluation indicators described in section 3.3 are calculated for each one of these BNs.

(insert table 5)

Table 5 shows the average results of these indicators for the 27 BNs for the training and the testing sets of data. With respect to the results obtained by the training set, the following findings could be highlighted:

- The values obtained for the all the performance indicators lie in the range between 0.42 and 0.76 . These values however, are in the range of values obtained by other researchers (Delen et al., 2006; Abdelwahab and Abdel-Aty, 2001).

- The highest values obtained for the indicators of Sensitivity and ROC area are 0.69-0.76 for the former, and in the range of 0.60-0.65 for the latter.

- The worst results were obtained for Specificity (between 0.42 and 0.49). This indicator is used to measure the ability of the model to classify the KSI cases. Since the number of SI cases is higher than the number of KSI cases, and thus the BNs are a data mining technique, better results are obtained for larger groups (SI in this case) from those obtained for smaller groups (Chang and Wang, 2006).

- As Accuracy and HMSS are indicators that take into account both Sensitivity and Specificity, their results are intermediate, ranging between 0.59 and 0.62 for Accuracy and 0.54 and 0.65 for HMSS.

In most of the cases (74\%), the values of the performance indicators obtained for the simplified BNs maintain or improve the results as compared to those of BN-18. Average values for each of the 27 BNs (training and testing sets) were tested for statistical significance $(\mathrm{p}<0.05)$ using least significant difference (LSD) ANOVA test.

Table 5 shows 7 BNs (BN-6a, BN-7c, BN-8a, BN-9a, BN-9b, BN-9c and BN-11b) that present statistically significant improvements in their performance indicators with respect to BN-18, with only a worsened value in one of their indicators. Having a closer look at these 7 BNs (see Table 3) it is 
observed that there are 7 variables (ACT, AGE, ATF, GEN, LIG, NOI, and OI) that repeat in more than $50 \%$ of these 7 BNs.

None of the previously built BNs was formed using this set of variables; therefore, a new BN (BN-7) was built using these 7 variables. Table 6 shows the average values of the indicators for this new BN. The results of all the performance indicators of this BN improve with respect to $\mathrm{BN}-18$ except for one indicator (specificity for the test set), and these improvements are statistically significant $(p<0.05)$ in $60 \%$ of the cases (accuracy, sensitivity and ROC area).

(insert Table 6)

Thus, it could be said that a simplified $\mathrm{BN}$ has been identified (BN-7), with only seven variables, whose results are similar or even better than those obtained by the original $\mathrm{BN}$ (BN-18) which includes all variables obtained from the police accidents report.

Figure 1 shows the structure of both $\mathrm{BN}-18$ and $\mathrm{BN}-7$. It shows that the complexity of the built $\mathrm{BN}$ is relieved when built using the subset of seven variables. The indicator used to measure the complexity of the built network is the number of arcs. The number of arcs was found to be 30 in the original BN (BN-18), whereas it was decreased to 9 arcs for the network of BN-7. The arcs in the networks indicate the existence of a relationship between variables. Where the arcs in a $\mathrm{BN}$ are not necessarily causal, that is, a BN can satisfy the probability distribution of the variables in the BN without the arcs being causal (Neapolitan, 2009). Thus, the arcs between variables in a non causal BN could imply a sort of interrelationship(s) among these variables.

The structure of the BN-7 network is similar to the network structure built using the 18 variables $(\mathrm{BN}-$ 18), keeping in mind that 11 variables have disappeared in BN-7. Thus, the structure of relationships between the variables SEV-ACT, SEV-LIG, SEV-GEN, SEV-OI, SEV-AGE, SEV-ATF, NOI-OI are the same in both BN-18 and BN-7, except for the two new connections between SEV-NOI and ACTOI that appeared in BN-7.

The variables that appear in BN-7 (accident type, age, atmospheric factors, gender, lighting, number of injuries and occupants involved) could be considered the ones that significantly affect the injury severity in a traffic accident.

\section{(insert Table 7)}

Setting evidences for the variables in $\mathrm{BN}-7$ could give indications of the values of variables that contribute to the occurrence of a killed or seriously injured (KSI) individual in a traffic accident. Table 7 assists in the identification of the variables and values that contribute the most to the occurrence of a KSI individual in a traffic accident. For each variable, the probability of a value was set to be 1 (setting simple evidence). Thus, the associated probability of severity was calculated.

Bold values in Table 7 highlight the highest probability values of a KSI for each variable. For example, Table 7 shows that the highest probability of KSI occurs when the lighting is insufficient ( $\mathrm{LIG}=\mathrm{I})$. BN-7 allows predicting that the probability of having a KSI accident is $58.91 \%$ if $\mathrm{LIG}=\mathrm{I}$. For the other six variables (ACT, AGE, ATF, GEN, NOI and OI), when information is only available about the variable itself, the highest probability of SEV=KSI occurs in the case of: ACT=head on; $\mathrm{AGE}=[18-25] ; \mathrm{ATF}=$ good weather; $\mathrm{GEN}=$ male; $\mathrm{NOI}=1$; and $\mathrm{OI}=1$.

Although some of these results could seem to be strange (for example, the probability of having KSI is higher when NOI=1 or when OI=1, instead of increasing the severity as NOI or OI increases), they are consistent with other results found in the literature: 
- Kockelman et al. (2002) found accident type to be one of the significant variables that affect the injury severity of traffic accidents. They found that head on crashes were more dangerous than angle crashes, left-side, and right-side crashes; they also found that they were significant in accidents that involved killed or seriously injured.

- Age was found to be a significant variable affecting the injury severity of traffic accidents by Tavris et al. (2001). They also found that male drivers in the age group (16-24) years were much more likely to be involved in killed or seriously injured accidents than those involving older drivers.

- Xie et al. (2009) found that adverse weather can actually lead to lower probability of suffering the most severe category of injuries. They explained their results by the fact that under such conditions, drivers tend to drive at lower speeds and be more cautious. They also found gender to be a significant variable; their results indicated that the chance for male drivers to suffer the most severe category of injuries is less than female drivers under the same crash circumstances. Their results coincided with the results found by Kockelman et al. (2002).

- Lighting has been found to be a significant variable defining injury severity in traffic accidents in several studies (Abdel-Aty, 2003; Helay et al., 2007 and Gray et al., 2008). They have found that more severe injuries are predicted during darkness.

- Scheetz et al. (2009) found that the number of injured occupants was a significant factor in classifying injury severity.

- Occupant involved in a traffic accident was found to be a significant variable by Dupont et al. (2010). They found that the higher the number of vehicles involved in the accident and the level of occupancy of these vehicles, the higher the probability for each car occupant to survive.

However, relationships between the variables and injury severity in traffic accidents are more subtle. The effect of variable's value does not always lead to the same outcome (e.g. not always that OI decreases the probability of KSI decreases). Simplified BN allow and facilitate analyzing these subtleties. For example, Table 7 shows that, in general, the probability of a KSI accident decreases with the number of OI:

$$
\begin{aligned}
& \mathrm{P}(\mathrm{SEV}=\mathrm{KSI} \mid \mathrm{OI}=1)=51.00 \% \\
& \mathrm{P}(\mathrm{SEV}=\mathrm{KSI} \mid \mathrm{OI}=2)=42.50 \% \\
& \mathrm{P}(\mathrm{SEV}=\mathrm{KSI} \mid \mathrm{OI}=>2)=42.13 \%
\end{aligned}
$$

However, Table 8 shows that the probability of SEV=KSI in the case of $\mathrm{HO}$ accidents that occurred in conditions of insufficient lighting ( $\mathrm{LIG}=\mathrm{I})$ and with only one injury $(\mathrm{NOI}=1)$ increases with the number of OI:

$$
\begin{aligned}
& \mathrm{P}(\mathrm{SEV}=\mathrm{KSI} \mid \mathrm{LIG}=\mathrm{I}, \mathrm{ACT}=\mathrm{HO}, \mathrm{NOI}=1, \mathrm{OI}=1)=57.13 \% \\
& \mathrm{P}(\mathrm{SEV}=\mathrm{KSI} \mid \mathrm{LIG}=\mathrm{I}, \mathrm{ACT}=\mathrm{HO}, \mathrm{NOI}=1, \mathrm{OI}=2)=67.14 \% \\
& \mathrm{P}(\mathrm{SEV}=\mathrm{KSI} \mid \mathrm{LIG}=\mathrm{I}, \mathrm{ACT}=\mathrm{HO}, \mathrm{NOI}=1, \mathrm{OI}=>2)=95.02 \%
\end{aligned}
$$


(insert Table 8)

Table 7 shows the probability of having an accident with SEV=KSI when knowing a priori the value of only one variable (simple evidences). Table 8 shows the probability of KSI when knowing a priori the value of more than one variable (multiple evidences). Based on the case that presents the highest probability in Table 7 (LIG=I), the probabilities with multiple evidences were calculated in a descending order (ACT, NOI, OI, AGE, GEN and ATF) (see Table 8). In each step, the highest probability value was selected and used for the next step.

Simplified BN allow this kind of analysis with multiple evidences. This analysis provides added value information with regard to the analysis with simple evidences. For example, Table 7 shows that the probability of an accident with SEV=KSI is $51 \%$ in the case of NOI $=1$ and $30 \%$ in the case of NOI $>1$. However, in $\mathrm{HO}$ accidents under insufficient lighting ( $\mathrm{ACT}=\mathrm{HO}$ and $\mathrm{LIG}=\mathrm{I}$ ) the probability of $\mathrm{SEV}=\mathrm{KSI}$ increases to $75.45 \%$ for NOI $=1$ and becomes $55.82 \%$ for NOI $>1$. Table 8 also shows that an accident with $\mathrm{LIG}=\mathrm{I}, \mathrm{ACT}=\mathrm{HO}, \mathrm{NOI}=1, \mathrm{OI}>2, \mathrm{AGE}=[18-25], \mathrm{GEN}=\mathrm{M}$ and $\mathrm{ATF}=\mathrm{GW}$ has a probability of $96.51 \%$ of having $\mathrm{SEV}=\mathrm{KSI}$.

\section{Summary and conclusions}

The main objective of this research work was to determine if it is possible to maintain or improve the performance of a model that is used to predict the injury severity of a traffic accident based on BNs reducing the number of variables considered in the analysis. The performance of the model was measured using five indicators (accuracy, specificity, sensitivity, HMSS and ROC area).

In order to perform this analysis 1,536 records of traffic accidents on rural highways with information about 18 variables that are related with the severity of the accidents based on the standard police reports used in Spain were used. 59 combinations of evaluator-search algorithms, which are commonly used in data mining, were used and 26 subsets of variables were identified.

Within these subsets of variables the variable accident type (ACT), lighting (LIG) and number of injuries (NOI) were selected the most times (over 95\%). Therefore, it could be said that these variables are the most significant ones in the classification of injury severity in traffic accidents, since they are included in almost all the selected subsets of variables.

For each one of these subsets of variables, 10 simplified BNs were built for the training stage and another 10 for the testing stage. In total, $540 \mathrm{BNs}$ were built using the hill climbing search algorithm and the MDL score (de Oña et al., 2011).

Comparing the average values of the indicators for each one of the simplified BNs with respect to the average values obtained for the original $\mathrm{BN}$ (BN-18), it is observed that, in most of cases (74\%), the performance indicators values for the simplified BNs maintained or improved in comparison with those of $\mathrm{BN}-18$. Therefore, it could be said that, in most cases, simplified networks maintain the performance of the original $\mathrm{BN}$.

Seven BNs were found to present statistically significant improvements in their performance indicators with respect to $\mathrm{BN}-18$ and only one value of these indicators get worsened. In more than $50 \%$ of these BNs the following variables are repeated: ACT, AGE, ATF, GEN, LIG, NOI and OI.

These 7 variables were used to built a new $\mathrm{BN}$ (BN-7). The results of the performance indicators of this $\mathrm{BN}$ with respect to $\mathrm{BN}-18$ improve practically in all the cases, and these improvements are statistically significant $(p<0.05)$ in $60 \%$ of the cases (accuracy, sensitivity and ROC area). 
Therefore, this research work shows that, for the analysis of the severity of road accidents by Bayesian networks on rural roads, it is possible to reduce the number of variables considered in more than $60 \%$ (from 18 to 7 variables) maintaining the performance of the models and reducing their complexity. Thus the findings of this research work agrees with Chang and Wang (2006) where they stated that if a model is applied only on a few important variables, more useful results could be obtained.

The procedure used to simplify BN models to analyze the severity of traffic accidents on rural highways could be also applied to other types of infrastructure (intersections, freeways, etc.) as well as to other models used to assess severity of traffic accidents (multinomial logit models, hierarchical logit models, probit models, etc.).

\section{Acknowledgements}

Support from Spanish Ministry of Science and Innovation (Research Project TRA2007-63564) as well as the data provided by the Spanish General Directorate of Traffic (DGT) are gratefully acknowledged.

\section{References}

1. Abdel-Aty, M. (2003). Analysis of driver injury severity levels at multiple locations using ordered probit models. Journal of Safety Research, 34, 597-603.

2. Abdelwahab, H.T., \& Abdel-Aty M.A. (2001). Development of Artificial Neural Network Models to Predict Driver Injury Severity in Traffic Accidents at Signalized Intersections. Transportation Research Record, 1746, 6-13.

3. Acid, S., de Campos, L.M., Fernández-Luna, J.M., Rodríguez, S., J.M., R. \& Salcedo, J.L. (2004) 'A comparison of Learning algorithms for Bayesian networks: a case study based on data from an emergency medical service, Artificial Intelligence in Medicine, 30, 215-232

4. Al-Ghamdi, A.S. (2002). Using logistic regression to estimate the influence of accident factors on accident severity, Accident Analysis and Prevention, 34, 729-741.

5. Bédard M., Guyatt, G.H., Stones, M.J., \& Hirdes, J.P. (2002). The independent contribution of driver, crash, and vehicle characteristics to driver fatalities, Accident Analysis and Prevention, 34, 717-727.

6. Chang, L.Y, \& Wang, H.W. (2006). Analysis of traffic injury severity: An application of nonparametric classification tree techniques. Accident Analysis and Prevention, 38, 1019-1027.

7. Chen, W.H, \& Jovanis, P.P. (2000). Method for identifying factors contributing to driver-injury severity in traffic crashes. Transportation Research Record, 1717, 1-9.

8. De Oña, J., Mujalli, R.O., \& Calvo, F. (2011). Analysis of traffic accident injury severity on Spanish rural highways using Bayesian networks. Accident Analysis and Prevention, 43 (1), $402-$ 411.

9. Delen, D., Sharda, R., \& Bessonov, M. (2006). Identifying significant predictors of injury severity in traffic accidents using a series of artificial neural networks. Accident Analysis and Prevention, $38,434-444$.

10. Dirección General de Tráfico - DGT. (2007). Anuario Estadístico 2007, NIPO: 128-08-161-7, Retrieved from http://www.dgt.es/.

11. Dupont, E., Martensen, H., Papadimitriou, E., \& Yannis, G. (2010). Risk and Protection factors in fatal accidents. Accident Analysis and Prevention, 42, 645-653.

12. García López, F., García Torres, M., Melián Batista, B., Moreno Pérez, J., \& Moreno-Vega, J. (2006). Solving feature subset selection problem by a Parallel Scatter Search . European Journal of Operational Research, 477-489.

13. Gray, R.C., Quddus, M.A. \& Evans, A. (2008). Injury severity analysis of accidents involv- ing young male drivers in Great Britain. Journal of Safety Research, 39, 483-495.

14. Glymour, C., Cooper, G. \& Chickering, D.M. (ed.) (1999). Computation Causation and Discovery, The AAAI Press.

15. Goldberg, D. (1989). Genetic algorithms in search, optimization and machine learning. AddisonWesley. 
16. Gutlein, M., Frank, E., Hall, M., \& Karwath, A. (2009). Large scale attribute selection using wrappers. - Proceedings of 2009 IEEE Symposium on Computational Intelligence and Data Mining, CIDM 2009, Washington.

17. Hall, M. (1998). Correlaion-based Feature Subset Selection for Machine Learning. Hamilton, New Zeland (Doctoral Dissertation).

18. Hedar, A.-R. W. (2008). Tabu search for attribute reduction in rough set theory. Soft Computing , 12 (9) 909-918.

19. Helai, H., Chor, C.H., \& Haque, M.M. (2008). Severity of driver injury and vehicle dam- age in traffic crashes at intersections: a Bayesian hierarchical analysis. Accident Analysis and Prevention, $40,45-54$.

20. Khhavi, R., \& John, G. (1997). Wrappers for feature subset selection. Artificial Intelligence, 97, 273-324.

21. Kockelman, K.M., \& Kweon, Y.J. (2002). Driver injury severity: an application of ordered probit models. Accident Analysis and Prevention, 34, 313-321.

22. Kopelias, P., Papadimitriou, F, Papandreou, K, \& Prevedouros, P. (2007). Urban Freeway Crash Analysis. Transportation Research Record: Journal Transportation Research Board, 2015, 123131.

23. Liu, H., \& Setiono, R. (1996). A probabilistic approach to feature selection- A filter solution. Proceedings of 13th International Conference on Machine Learning.

24. Madden, M. G. (2009). On the classification performance of TAN and general Bayesian networks. Journal of Knowledge-Based Systems, 22, 489-495.

25. Milton, J.C., Shankar, V.N., \& Mannering, F.L. (2008). Highway accident severities and the mixed logit model: An exploratory empirical analysis. Accident Analysis and Prevention, 40, 260266.

26. Mittal, A., Kassim, A., \& Tan, T. (2007). Bayesian network technologies: Applications and graphical models. IGI Publishing.

27. Moore, A., \& Lee, M. (1994). Efficient algorithms for minimizing cross validation error. Proceedings of 11th International Conference on Machine Lerning.

28. Neapolitan, R.E. (2004). Learning Bayesian Networks, Prentice Hall.

29. Neapolitan, R.E. (2009). Probabilistic Methods for Bioinformatics. San Francisco, California: Morgan Kaufmann Publishers.

30. Pearl, J. (1984). Heuristics: Intelligent search strategies for computer problem solving. AddisonWesley.

31. Pearl J. (2000). Causality: Models, Reasoning and Inference. Cambridge: Cambridge University Press.

32. Russell, S., \& Norvig, P. (2003). Artificial Intelligence: A modern approach . Upper Saddle River, New Jersey: Prentice Hall.

33. Scheetz, L.J., Zhang, J., \& Kolassa, J. (2003). Classification tree to identify severe and moderate injuries in young and middle aged adults. Artificial Intelligence in Medicine, 45, 1-10.

34. Simoncic, M. (2004). A Bayesian network model of two-car accidents. Journal of transportation and Statistics, 7, 13-25.

35. Tavris, D.R., Kuhn, E.M., \& Layde, P.M. (2001). Age and gender patterns in motor vehicle crash injuries: importance of type of crash and occupant role. Accident Analysis and Prevention, 33, 167-172.

36. Witten, I. H., \& Frank, E. (2005). Data Mining: Practical Machine Learning Tools and Techniques ( $2^{\text {nd }}$ Edition). San Francisco, California: Morgan Kaufmann Publishers.

37. Xie, Y., Zhang, Y., \& Liang, F. (2009). Crash Injury Severity Analysis Using Bayesian Ordered Probit Models. Journal of Transportation Engineering ASCE, 135 (1),18-25.

38. Yamamoto, T., \& Shankar, V.N. (2004). Bivariate ordered-response probit model of driver's and passenger's injury severities in collisions with fixed objects. Accident Analysis and Prevention, 36, 869-876.

39. Yau, K.K.W., Lo, H.P., \& Fung, S.H.H. (2006). Multiple-vehicle traffic accidents in Hong Kong, Accident Analysis and Prevention, 38,1157-1161. 


\section{List of Figures:}

Figure 1: BN structure for BN-18 and BN-7.

\section{List of Tables:}

Table 1: Variables, values and actual classification by severity

Table 2: Search-evaluator combinations which were found to be incompatible

Table 3: Selected variables for different combinations of evaluator-search method

Table 4: Number of times each variable is selected

Table 5: Average values for accuracy, sensitivity, specificity, HMSS and ROC area for the 27 built BNs (training and test data).

Table 6: Average values for accuracy, sensitivity, specificity, HMSS and ROC area for BN-18 and BN-7 (training and test data).

Table 7: Inference results for simple evidences in BN-7

Table 8: Inference results for multiple evidences in $\mathrm{BN}-7$ 
VITAE

Juan de Oña is an Associate Professor in the Department of Civil Engineering at the University of Granada. M.Eng. in Civil Engineering (1996), Ecole Nationale de Ponts et Chaussées, Paris (France). M.Sc. in Transportation (1999), Polytechnic University of Madrid (Spain). He holds a Ph.D. in Transportation Engineering (2001) from the University of Granada. He is the Director of the Transportation and Safety Research Group, Secretariat-General of Universities, Research and Technology of Andalucía. His current fields of interest include road safety, transport planning and management, and railways management.

Randa Oqab Mujalli is a PhD student in the Department of Civil Engineering at the University of Granada. She holds both a BSc in Civil Engineering (2005) and an MSc in Transportation Engineering (2007) from Jordan University of Science and Technology, Irbid (Jordan). She is currently a Research Assistant in the Division of Transportation at the University of Granada, Granada (Spain). Her fields of interest include traffic safety, transportation planning and management, highway design, and Artificial intelligence and soft computing applications in transportation engineering. 

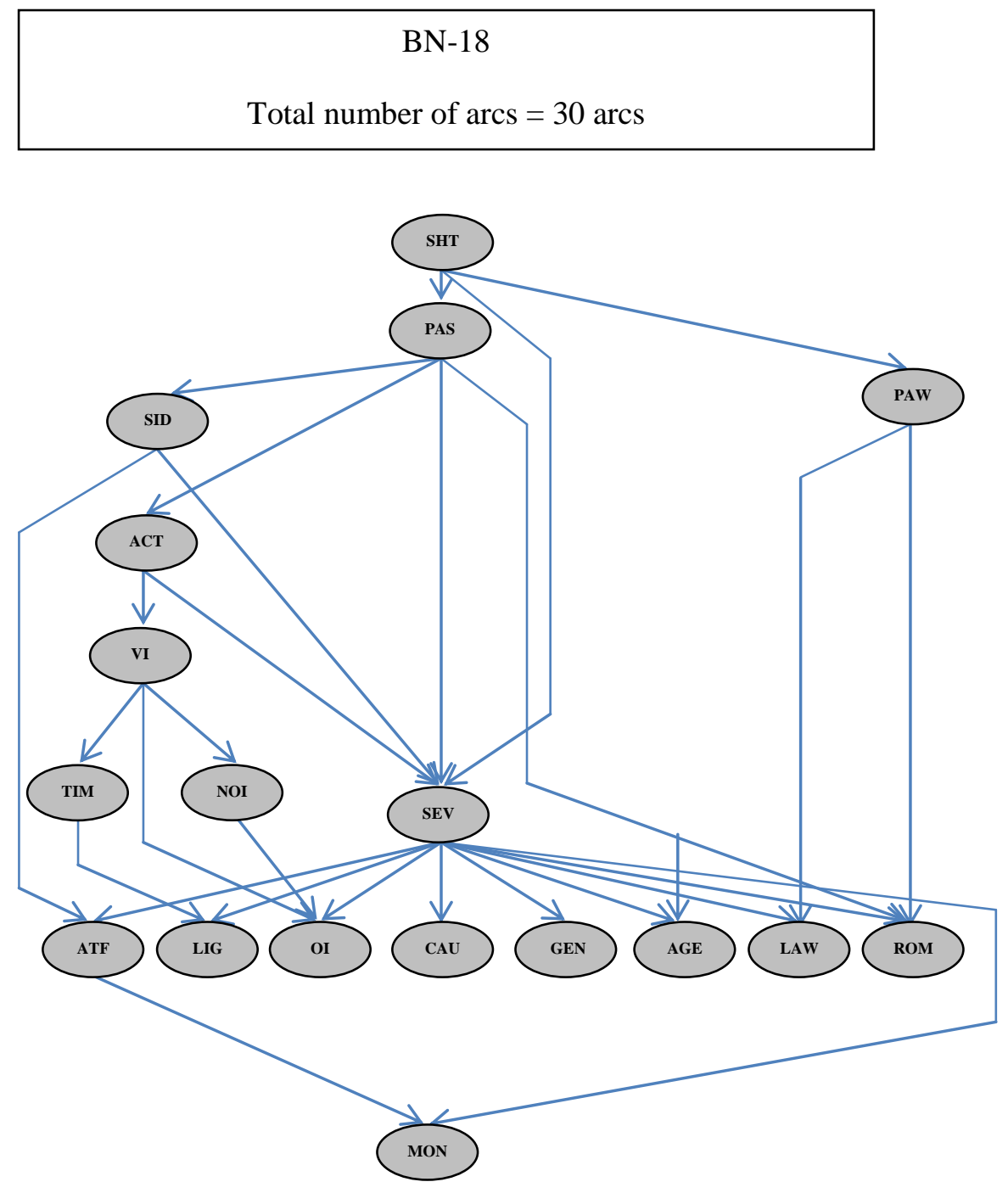

BN-7

Total number of $\operatorname{arcs}=9$ arcs

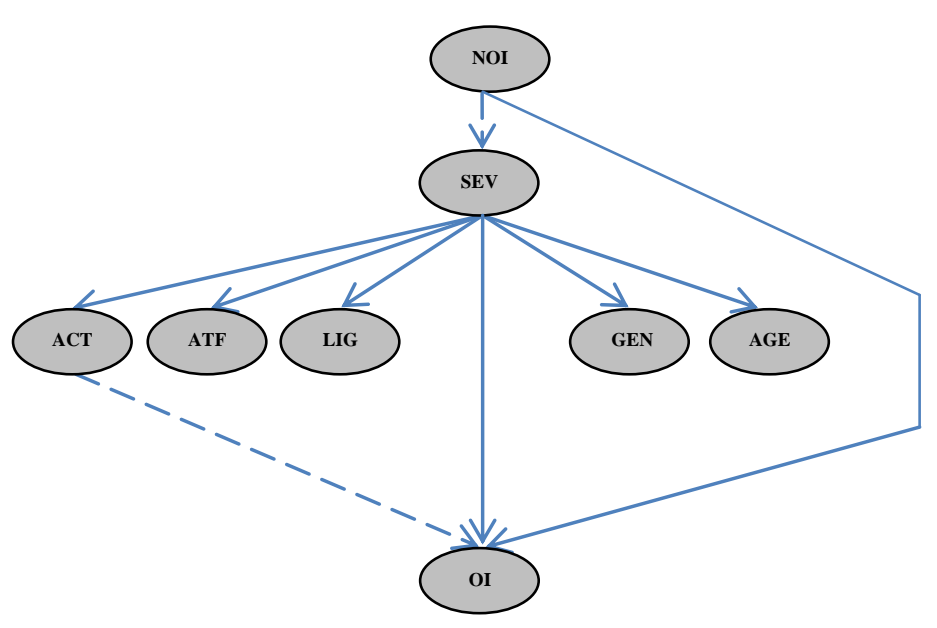


Table 1: Variables, values and actual classification by severity

\begin{tabular}{|c|c|c|c|c|c|c|}
\hline \multirow{3}{*}{$\begin{array}{l}\text { Variables } \\
\text { ACT: accident } \\
\text { Type }\end{array}$} & \multirow{3}{*}{$\begin{array}{l}\text { Values } \\
\text { AS: angle or side collision } \\
\text { CF: fixed objects } \\
\text { HO: head on } \\
\text { O: other } \\
\text { PU: pile up } \\
\text { R: rollover } \\
\text { SP: straight path }\end{array}$} & \multicolumn{4}{|c|}{ SEV* } & \multirow{2}{*}{ Total } \\
\hline & & \multicolumn{2}{|r|}{ SI } & \multicolumn{2}{|r|}{ KSI } & \\
\hline & & $\begin{array}{l}381 \\
99 \\
84 \\
75 \\
33 \\
163 \\
17 \\
\end{array}$ & $\begin{array}{l}61.45 \% \\
52.94 \% \\
40.58 \% \\
59.06 \% \\
78.57 \% \\
49.39 \% \\
73.91 \%\end{array}$ & $\begin{array}{l}239 \\
88 \\
123 \\
52 \\
9 \\
167 \\
6 \\
\end{array}$ & $\begin{array}{l}38.55 \% \\
47.06 \% \\
59.42 \% \\
40.94 \% \\
21.43 \% \\
50.61 \% \\
26.09 \%\end{array}$ & $\begin{array}{l}620 \\
187 \\
207 \\
127 \\
42 \\
330 \\
23 \\
\end{array}$ \\
\hline AGE: age & $\begin{array}{l}{[18-25]} \\
(25-64] \\
>64\end{array}$ & $\begin{array}{l}225 \\
586 \\
41 \\
\end{array}$ & $\begin{array}{l}50.34 \% \\
57.73 \% \\
55.41 \%\end{array}$ & $\begin{array}{l}222 \\
429 \\
33\end{array}$ & $\begin{array}{l}49.66 \% \\
42.27 \% \\
44.59 \%\end{array}$ & $\begin{array}{l}447 \\
1015 \\
74\end{array}$ \\
\hline $\begin{array}{l}\text { ATF: atmospheric } \\
\text { Factors }\end{array}$ & $\begin{array}{l}\text { GW: good weather } \\
\text { HR: heavy rain } \\
\text { LR: light rain } \\
\text { O: other }\end{array}$ & $\begin{array}{l}730 \\
23 \\
84 \\
15\end{array}$ & $\begin{array}{l}54.23 \% \\
71.88 \% \\
61.76 \% \\
68.18 \%\end{array}$ & $\begin{array}{l}616 \\
9 \\
52 \\
7\end{array}$ & $\begin{array}{l}45.77 \% \\
28.13 \% \\
38.24 \% \\
31.81 \%\end{array}$ & $\begin{array}{l}1346 \\
32 \\
136 \\
22\end{array}$ \\
\hline CAU: cause & $\begin{array}{l}\text { DC: driver characteristics } \\
\text { OF: other factors } \\
\text { RC: road characteristics } \\
\text { VC: vehicle charactersitics }\end{array}$ & $\begin{array}{l}791 \\
50 \\
3 \\
8\end{array}$ & $\begin{array}{l}54.93 \% \\
66.67 \% \\
75.00 \% \\
47.06 \%\end{array}$ & $\begin{array}{l}649 \\
25 \\
1 \\
9\end{array}$ & $\begin{array}{l}45.07 \% \\
33.33 \% \\
25.00 \% \\
52.94 \%\end{array}$ & $\begin{array}{l}1440 \\
75 \\
4 \\
17\end{array}$ \\
\hline DAY: day & $\begin{array}{l}\text { BW: beginning of week } \\
\text { EW: end of week } \\
\text { F: festive } \\
\text { WD: week day } \\
\text { WE: week end }\end{array}$ & $\begin{array}{l}123 \\
132 \\
29 \\
325 \\
243\end{array}$ & $\begin{array}{l}60.29 \% \\
57.14 \% \\
61.70 \% \\
55.65 \% \\
51.70 \%\end{array}$ & $\begin{array}{l}81 \\
99 \\
18 \\
259 \\
227\end{array}$ & $\begin{array}{l}39.71 \% \\
42.86 \% \\
38.30 \% \\
44.35 \% \\
48.30 \%\end{array}$ & $\begin{array}{l}204 \\
231 \\
47 \\
584 \\
470\end{array}$ \\
\hline GEN : gender & $\begin{array}{l}\text { F: female } \\
\text { M: male }\end{array}$ & $\begin{array}{l}148 \\
704\end{array}$ & $\begin{array}{l}63.79 \% \\
53.99 \%\end{array}$ & $\begin{array}{l}84 \\
600\end{array}$ & $\begin{array}{l}36.21 \% \\
46.01 \%\end{array}$ & $\begin{array}{l}232 \\
1304\end{array}$ \\
\hline LAW: lane width & $\begin{array}{l}\text { THI: thin: }<3.25 \mathrm{~m} \\
\text { MED: medium: } 3.25 \mathrm{~m}<=\mathrm{L}<=3.75 \mathrm{~m} \\
\text { WID: wide: }>3.75 \mathrm{~m}\end{array}$ & $\begin{array}{l}19 \\
176 \\
657\end{array}$ & $\begin{array}{l}67.86 \% \\
51.16 \% \\
56.44 \%\end{array}$ & $\begin{array}{l}9 \\
168 \\
507\end{array}$ & $\begin{array}{l}32.14 \% \\
48.84 \% \\
43.56 \%\end{array}$ & $\begin{array}{l}28 \\
344 \\
1164\end{array}$ \\
\hline LIG: lighting & $\begin{array}{l}\text { D: dusk } \\
\text { DL: daylight } \\
\text { I: insufficient } \\
\text { S: sufficient } \\
\text { W: without lighting }\end{array}$ & \begin{tabular}{|l|}
52 \\
573 \\
27 \\
36 \\
164 \\
\end{tabular} & $\begin{array}{l}61.18 \% \\
58.65 \% \\
54.00 \% \\
59.02 \% \\
45.18 \% \\
\end{array}$ & $\begin{array}{l}33 \\
404 \\
23 \\
25 \\
199 \\
\end{array}$ & \begin{tabular}{|l}
$38.82 \%$ \\
$41.35 \%$ \\
$46.00 \%$ \\
$40.98 \%$ \\
$54.82 \%$ \\
\end{tabular} & $\begin{array}{l}85 \\
977 \\
50 \\
61 \\
363 \\
\end{array}$ \\
\hline MON: month & $\begin{array}{l}\text { AUT: autumn } \\
\text { SPR: spring } \\
\text { SUM: summer } \\
\text { WIN: winter }\end{array}$ & $\begin{array}{l}218 \\
206 \\
246 \\
182\end{array}$ & $\begin{array}{l}54.23 \% \\
59.03 \% \\
56.55 \% \\
52.00 \%\end{array}$ & $\begin{array}{l}184 \\
143 \\
189 \\
168\end{array}$ & $\begin{array}{l}45.77 \% \\
40.97 \% \\
43.45 \% \\
48.00 \%\end{array}$ & $\begin{array}{l}402 \\
349 \\
435 \\
350\end{array}$ \\
\hline $\begin{array}{l}\text { NOI: number of } \\
\text { Injuries }\end{array}$ & $\begin{array}{l}1 \\
>1\end{array}$ & $\begin{array}{l}539 \\
313\end{array}$ & $\begin{array}{l}49.95 \% \\
68.49 \%\end{array}$ & $\begin{array}{l}540 \\
144\end{array}$ & $\begin{array}{l}50.05 \% \\
31.51 \%\end{array}$ & $\begin{array}{l}1079 \\
457\end{array}$ \\
\hline
\end{tabular}




\begin{tabular}{|c|c|c|c|c|c|c|}
\hline $\begin{array}{l}\text { OI: occupants } \\
\text { involved }\end{array}$ & $\begin{array}{l}1 \\
2 \\
>2\end{array}$ & $\begin{array}{l}229 \\
374 \\
249\end{array}$ & $\begin{array}{l}51.58 \% \\
55.99 \% \\
58.73 \%\end{array}$ & $\begin{array}{l}215 \\
294 \\
175\end{array}$ & $\begin{array}{l}48.42 \% \\
44.01 \% \\
41.27 \%\end{array}$ & $\begin{array}{l}444 \\
668 \\
424\end{array}$ \\
\hline $\begin{array}{l}\text { PAS: paved } \\
\text { shoulder }\end{array}$ & $\begin{array}{l}\text { missing values } \\
\mathrm{N}: \text { no } \\
\mathrm{Y} \text { : yes }\end{array}$ & $\begin{array}{l}66 \\
253 \\
533 \\
\end{array}$ & $\begin{array}{l}51.56 \% \\
57.11 \% \\
55.23 \% \\
\end{array}$ & $\begin{array}{l}62 \\
190 \\
432 \\
\end{array}$ & $\begin{array}{l}48.44 \% \\
42.89 \% \\
44.77 \% \\
\end{array}$ & $\begin{array}{l}128 \\
443 \\
965\end{array}$ \\
\hline $\begin{array}{l}\text { PAW: pavement } \\
\text { width }\end{array}$ & $\begin{array}{l}\text { THI: thin: }<6 \mathrm{~m} \\
\text { MED: medium: } 6 \mathrm{~m}<=1 \mathrm{aw}<=7 \mathrm{~m} \\
\text { WID: wide: }>7 \mathrm{~m}\end{array}$ & $\mid \begin{array}{l}95 \\
209 \\
548\end{array}$ & $\begin{array}{l}53.98 \% \\
54.29 \% \\
56.21 \%\end{array}$ & $\begin{array}{l}81 \\
176 \\
427\end{array}$ & $\begin{array}{l}46.02 \% \\
45.71 \% \\
43.79 \%\end{array}$ & $\begin{array}{l}176 \\
385 \\
975\end{array}$ \\
\hline $\begin{array}{l}\text { ROM: pavement } \\
\text { markings }\end{array}$ & $\begin{array}{l}\text { DME: does not exist or was deleted } \\
\text { DMR: define margins of roadway } \\
\text { SLD: separate lanes and defined road } \\
\text { margins } \\
\text { SLO: separate lanes only }\end{array}$ & $\begin{array}{l}60 \\
60 \\
714 \\
18\end{array}$ & $\begin{array}{l}58.25 \% \\
57.69 \% \\
55.26 \% \\
48.65 \% \\
\end{array}$ & $\begin{array}{l}43 \\
44 \\
578 \\
19\end{array}$ & $\begin{array}{l}41.75 \% \\
42.31 \% \\
44.74 \% \\
51.35 \%\end{array}$ & $\begin{array}{l}103 \\
104 \\
1292 \\
37\end{array}$ \\
\hline $\begin{array}{l}\text { SHT: Shoulder } \\
\text { type }\end{array}$ & $\begin{array}{l}\text { NOS: does not exist } \\
\text { THI: thin: }<1.5 \mathrm{~m} \\
\text { MED: medium: } 1.5 \mathrm{~m}<=\text { sht }<2.50 \mathrm{~m} \\
\text { WID: wide }>=2.50 \mathrm{~m}\end{array}$ & $\begin{array}{l}311 \\
402 \\
133 \\
6\end{array}$ & $\begin{array}{l}55.24 \% \\
54.47 \% \\
58.85 \% \\
66.67 \% \\
\end{array}$ & $\begin{array}{l}252 \\
336 \\
93 \\
3\end{array}$ & $\begin{array}{l}44.76 \% \\
45.53 \% \\
41.15 \% \\
33.33 \% \\
\end{array}$ & $\begin{array}{l}563 \\
738 \\
226 \\
9\end{array}$ \\
\hline $\begin{array}{l}\text { SID: sight } \\
\text { distance }\end{array}$ & $\begin{array}{l}\text { A: atmospheric } \\
\text { B: building } \\
\text { O: other } \\
\text { T: topological } \\
\text { V: vegetation } \\
\text { WR: without restriction }\end{array}$ & $\begin{array}{l}26 \\
10 \\
6 \\
187 \\
6 \\
617\end{array}$ & $\begin{array}{l}81.25 \% \\
55.56 \% \\
66.67 \% \\
55.49 \% \\
54.55 \% \\
54.65 \%\end{array}$ & $\begin{array}{l}6 \\
8 \\
3 \\
150 \\
5 \\
512\end{array}$ & $\begin{array}{l}18.75 \% \\
44.44 \% \\
33.34 \% \\
44.51 \% \\
45.45 \% \\
45.35 \%\end{array}$ & $\begin{array}{l}32 \\
18 \\
9 \\
337 \\
11 \\
1129\end{array}$ \\
\hline TIM: time & \begin{tabular}{|l}
$0-6]$ \\
$(6-12]$ \\
$(12-18]$ \\
$(18-24)$
\end{tabular} & $\begin{array}{l}99 \\
236 \\
314 \\
203\end{array}$ & $\begin{array}{l}46.26 \% \\
57.99 \% \\
57.72 \% \\
54.72 \% \\
\end{array}$ & $\begin{array}{l}115 \\
171 \\
230 \\
168\end{array}$ & $\begin{array}{l}53.74 \% \\
42.01 \% \\
42.28 \% \\
45.28 \%\end{array}$ & $\begin{array}{l}214 \\
407 \\
544 \\
371\end{array}$ \\
\hline $\begin{array}{l}\text { VI: vehicles } \\
\text { involved }\end{array}$ & $\begin{array}{l}1 \\
2 \\
>2\end{array}$ & $\begin{array}{l}316 \\
468 \\
68 \\
\end{array}$ & $\begin{array}{l}52.06 \% \\
56.73 \% \\
65.38 \% \\
\end{array}$ & $\begin{array}{l}291 \\
357 \\
36 \\
\end{array}$ & $\begin{array}{l}47.94 \% \\
43.27 \% \\
34.62 \% \\
\end{array}$ & $\begin{array}{l}607 \\
825 \\
104 \\
\end{array}$ \\
\hline Total & & 852 & $55.47 \%$ & 684 & $44.53 \%$ & 1536 \\
\hline
\end{tabular}

* SEV: injury severity; SI: slight injured; KSI: killed or seriously injured 
Table 2: Search-evaluator combinations which were found to be incompatible

\begin{tabular}{|l|l|}
\hline Search Method & Evaluator \\
\hline \multirow{5}{*}{ Race Search } & CfsSubsetEval \\
& ConsistencySubsetEval \\
& WrapperSubsetEavl \\
& FilteredSubsetEval \\
& CostSensitiveSubsetEval \\
\hline \multirow{2}{*}{ Tabu Search } & ClassifierSubsetEval \\
& WrapperSubsetEavl \\
\hline
\end{tabular}


Table 3: Selected variables for different combinations of evaluator-search method.

\begin{tabular}{|c|c|c|c|c|}
\hline \multirow{2}{*}{$\begin{array}{l}\text { Number } \\
\text { of } \\
\text { variables }\end{array}$} & \multicolumn{2}{|r|}{ Variable selection method } & \multirow{2}{*}{ Variables selected } & \multirow{2}{*}{$\mathbf{B N}$} \\
\hline & Evaluator & Search Method & & \\
\hline 18 & \multicolumn{2}{|c|}{ The original training set of variables } & $\begin{array}{l}\text { ACT, AGE, ATF, CAU, DAY, GEN, LAW, LIG, } \\
\text { MON, NOI, OI, PAS, PAW, ROM, SHT, SID, } \\
\text { TIM, VI }\end{array}$ & $\mathrm{BN}-18$ \\
\hline \multirow{3}{*}{4} & CFS & $\begin{array}{l}\text { Best first, Exhaustive, Greedy stepwise, } \\
\text { Linear forward selection, Rank, Scatter V1, } \\
\text { Tabu }\end{array}$ & \multirow{3}{*}{ ACT, ATF, LIG, NOI } & \multirow{3}{*}{$\mathrm{BN}-4$} \\
\hline & Cost sensitive & $\begin{array}{l}\text { Best first, Exhaustive, Greedy stepwise, } \\
\text { Linear forward selection, Random, Rank, } \\
\text { Scatter V1, Tabu }\end{array}$ & & \\
\hline & Filtered & Rank & & \\
\hline \multirow{3}{*}{5} & CFS & Genetic, Random & ACT, ATF, LIG, NOI, SID & $\mathrm{BN}-5 \mathrm{a}$ \\
\hline & Classifier & Subset Size Forward Selection & ACT, ATF, CAU, LIG, NOI & $\mathrm{BN}-5 \mathrm{~b}$ \\
\hline & Wrapper & Scatter V1 & ACT, DAY, LIG, NOI, OI & $\mathrm{BN}-5 \mathrm{c}$ \\
\hline \multirow{4}{*}{6} & Classifier & Scatter V1 & ACT, ATF, GEN, LIG, MON, NOI & BN-6a \\
\hline & Cost sensitive & Genetic & ACT, ATF, LIG, NOI, SHT, SID & $\mathrm{BN}-6 \mathrm{~b}$ \\
\hline & Filtered & Random & ACT, ATF, LAW, LIG, NOI, SID & $\mathrm{BN}-6 \mathrm{c}$ \\
\hline & Wrapper & $\begin{array}{l}\text { Greedy stepwise, Subset Size Forward } \\
\text { Selection }\end{array}$ & ACT, AGE, GEN, LIG, MON, SHT & BN-6d \\
\hline \multirow{5}{*}{7} & CFS & Subset Size Forward Selection & \multirow[b]{2}{*}{ ACT, ATF, GEN, LAW, LIG, NOI, SID } & \multirow[b]{2}{*}{$\mathrm{BN}-7 \mathrm{a}$} \\
\hline & Filtered & $\begin{array}{l}\text { Best first, Exhaustive, Greedy stepwise, } \\
\text { Linear forward selection, Scatter V1, } \\
\text { Subset Size Forward Selection, Tabu }\end{array}$ & & \\
\hline & Cost sensitive & Subset Size Forward Selection & ACT, ATF, LAW, LIG, NOI, SHT, SID & $\mathrm{BN}-7 \mathrm{~b}$ \\
\hline & Classifier & Greedy stepwise & ACT, AGE, ATF, GEN, LIG, NOI, OI & $\mathrm{BN}-7 \mathrm{c}$ \\
\hline & Wrapper & Random & ACT, GEN, LIG, NOI, OI, SHT, VI & BN-7d \\
\hline \multirow{2}{*}{8} & Classifier & Race & ACT, AGE, GEN, LAW, LIG, NOI, OI, ROM & $\mathrm{BN}-8 \mathrm{a}$ \\
\hline & Filtered & Genetic & ACT, ATF, GEN, LAW, LIG, MON, NOI, SID & $\mathrm{BN}-8 \mathrm{~b}$ \\
\hline \multirow{3}{*}{9} & \multirow{3}{*}{ Wrapper } & Best first & ACT, ATF, GEN, LAW, LIG, NOI, OI, PAS, PAW & BN-9a \\
\hline & & Exhaustive & ACT, AGE, ATF, GEN, LIG, MON, NOI, OI, VI & $\mathrm{BN}-9 \mathrm{~b}$ \\
\hline & & Genetic & ACT, ATF, DAY, GEN, LIG, NOI, OI, PAS, PAW & $\mathrm{BN}-9 \mathrm{c}$ \\
\hline \multirow{2}{*}{11} & Classifier & Exhaustive & $\begin{array}{l}\text { ACT, CAU, DAY, GEN, LIG, MON, NOI, OI, } \\
\text { PAS, TIM, VI }\end{array}$ & $\mathrm{BN}-11 \mathrm{a}$ \\
\hline & Wrapper & Linear forward selection & $\begin{array}{l}\text { ACT, AGE, ATF, DAY, GEN, LIG, MON, NOI, } \\
\text { OI, SHT, VI }\end{array}$ & $\mathrm{BN}-11 \mathrm{~b}$ \\
\hline 12 & Classifier & Random & $\begin{array}{l}\text { ACT, AGE, CAU, GEN, LIG, MON, NOI, OI, } \\
\text { PAS, SID, TIM, VI }\end{array}$ & $\mathrm{BN}-12$ \\
\hline 14 & Consistency & $\begin{array}{l}\text { Best first, Exhaustive, Greedy stepwise, } \\
\text { Linear forward selection, Rank, Scatter } \\
\text { V1, Subset Size Forward Selection, Tabu }\end{array}$ & $\begin{array}{l}\text { ACT, AGE, DAY, GEN, LAW, LIG, MON, NOI, } \\
\text { OI, PAS, PAW, SHT, SID, TIM }\end{array}$ & $\mathrm{BN}-14$ \\
\hline \multirow{2}{*}{15} & Consistency & Genetic & $\begin{array}{l}\text { ACT, ATF, CAU, DAY, GEN, LAW, LIG, NOI, } \\
\text { OI, PAS, PAW, ROM, SHT, TIM, VI }\end{array}$ & $\mathrm{BN}-15 \mathrm{a}$ \\
\hline & Classifier & Best first & $\begin{array}{l}\text { ACT, AGE, CAU, DAY, GEN, LAW, LIG, MON, } \\
\text { NOI, OI, PAS, PAW, SHT, SID, TIM }\end{array}$ & $\mathrm{BN}-15 \mathrm{~b}$ \\
\hline \multirow{3}{*}{16} & \multirow{2}{*}{ Classifier } & Genetic & $\begin{array}{l}\text { ACT, ATF, CAU, DAY, GEN, LAW, LIG, MON, } \\
\text { NOI, OI, PAS, PAW, ROM, SHT, TIM, VI }\end{array}$ & BN-16a \\
\hline & & Liner forward selection & $\begin{array}{l}\text { ACT, AGE, ATF, CAU, DAY, GEN, LIG, MON, } \\
\text { NOI, OI, PAS, PAW, ROM, SHT, SID, VI }\end{array}$ & $\mathrm{BN}-16 \mathrm{~b}$ \\
\hline & Consistency & Random & $\begin{array}{l}\text { ACT, AGE, ATF, CAU, DAY, GEN, LAW, LIG, } \\
\text { MON, NOI, OI, PAS, PAW, SHT, SID, TIM }\end{array}$ & $\mathrm{BN}-16 \mathrm{c}$ \\
\hline
\end{tabular}


Table 4: Number of times each variable is selected

\begin{tabular}{|c|c|}
\hline Variable & Number of times variable has been selected \\
\hline ACT & 58 \\
\hline LIG & 58 \\
\hline NOI & 56 \\
\hline ATF & 42 \\
\hline GEN & 34 \\
\hline LAW & 26 \\
\hline SID & 26 \\
\hline OI & 25 \\
\hline MON & 21 \\
\hline SHT & 20 \\
\hline AGE & 19 \\
\hline DAY & 18 \\
\hline PAS & 18 \\
\hline PAW & 16 \\
\hline TIM & 15 \\
\hline CAU & 9 \\
\hline VI & 9 \\
\hline ROM & 5 \\
\hline
\end{tabular}


Table 5: Average values for accuracy, sensitivity, specificity, HMSS and ROC area for the 27 built BNs (training and test data).

\begin{tabular}{|c|c|c|c|c|c|c|c|c|c|c|c|}
\hline \multirow{3}{*}{$\begin{array}{l}\text { Number of selected } \\
\text { variables }\end{array}$} & \multirow[t]{3}{*}{$\mathrm{BN}$} & \multicolumn{10}{|c|}{ BN results } \\
\hline & & training & test & training & test & training & test & training & test & training & test \\
\hline & & \multicolumn{2}{|c|}{ Accuracy } & \multicolumn{2}{|c|}{ Sensitivity } & \multicolumn{2}{|c|}{ Specifity } & \multicolumn{2}{|c|}{ HMSS } & \multicolumn{2}{|c|}{ ROC area } \\
\hline All the variables (18) & BN-18 & 0,59 & 0,58 & 0,71 & 0,65 & 0,45 & 0,49 & 0,55 & 0,56 & 0,62 & 0,61 \\
\hline 4 & $\mathrm{BN}-4$ & $\mathbf{0 , 6 0}$ & $\mathbf{0 , 5 9}$ & 0,71 & 0,68 & 0,46 & 0,48 & 0,56 & 0,56 & $\mathbf{0 , 6 3}$ & 0,61 \\
\hline \multirow{3}{*}{5} & $\mathrm{BN}-5 \mathrm{a}$ & 0,59 & 0,57 & 0,70 & 0,68 & 0,45 & 0,45 & 0,55 & 0,54 & 0,62 & 0,60 \\
\hline & $\mathrm{BN}-5 \mathrm{~b}$ & $\mathbf{0 , 6 0}$ & $\mathbf{0 , 5 9}$ & 0,71 & 0,68 & $\mathbf{0 , 4 7}$ & 0,49 & 0,56 & 0,56 & $\mathbf{0 , 6 3}$ & 0,61 \\
\hline & $\mathrm{BN}-5 \mathrm{c}$ & $0,61 *$ & $0,61 *$ & $0,75 *$ & $0,73 *$ & 0,44 & 0,46 & 0,55 & 0,56 & $0,63 *$ & 0,62 \\
\hline \multirow{4}{*}{6} & BN-6a & $\mathbf{0 , 6 0}$ & $0,60 *$ & 0,70 & 0,67 & $\mathbf{0 , 4 9 *}$ & 0,49 & $\mathbf{0 , 5 8}$ & $\mathbf{0 , 5 7}$ & $0,64 *$ & 0,62 \\
\hline & BN-6b & 0,59 & 0,57 & 0,71 & 0,67 & 0,45 & 0,45 & 0,55 & 0,54 & 0,62 & 0,60 \\
\hline & BN-6c & 0,59 & 0,57 & 0,70 & 0,67 & 0,45 & 0,46 & 0,55 & 0,54 & 0,62 & 0,60 \\
\hline & BN-6d & 0,60 & 0,57 & 0,74 & $0,69 *$ & 0,42 & $0,42 *$ & 0,54 & $0,52 *$ & $0,60 *$ & $0,58 *$ \\
\hline \multirow{4}{*}{7} & $\mathrm{BN}-7 \mathrm{a}$ & 0,60 & 0,57 & 0,70 & 0,66 & 0,47 & 0,48 & 0,56 & 0,55 & 0,62 & 0,60 \\
\hline & $\mathrm{BN}-7 \mathrm{~b}$ & 0,59 & 0,57 & 0,70 & 0,66 & 0,45 & 0,46 & 0,55 & 0,54 & 0,62 & 0,60 \\
\hline & $\mathrm{BN}-7 \mathrm{c}$ & $0,62 *$ & $0,60 *$ & 0,74 & $0,70 *$ & 0,47 & 0,48 & 0,57 & $\mathbf{0 , 5 7}$ & $0,64 *$ & 0,63 \\
\hline & BN-7d & $0,61 *$ & $\mathbf{0 , 5 9}$ & $\mathbf{0 , 7 6}$ & 0,72 & 0,42 & 0,44 & 0,54 & 0,54 & $0,64 *$ & 0,62 \\
\hline \multirow{2}{*}{8} & $\mathrm{BN}-8 \mathrm{a}$ & $0,62 *$ & $0,60 *$ & $0,75 *$ & $0,71 *$ & 0,46 & 0,47 & $\mathbf{0 , 5 7}$ & 0,56 & $0,64 *$ & $0,63 *$ \\
\hline & $\mathrm{BN}-8 \mathrm{~b}$ & 0,59 & 0,58 & 0,69 & 0,67 & 0,47 & 0,48 & 0,56 & $0,56 *$ & 0,63 & 0,60 \\
\hline \multirow{3}{*}{9} & BN-9a & $0,61 *$ & $0,60 *$ & $0,74 *$ & $0,70 *$ & 0,46 & 0,47 & 0,56 & 0,56 & $0,65 *$ & $0,63 *$ \\
\hline & $\mathrm{BN}-9 \mathrm{~b}$ & $0,62 *$ & $\mathbf{0 , 5 9}$ & $0,75 *$ & $0,71 *$ & 0,46 & 0,47 & $\mathbf{0 , 5 7}$ & 0,56 & $0,64 *$ & 0,62 \\
\hline & $\mathrm{BN}-9 \mathrm{c}$ & $0,61 *$ & 0,59 & $\mathbf{0 , 7 3}$ & $0,69 *$ & 0,46 & 0,48 & 0,56 & 0,56 & $0,65 *$ & 0,63 \\
\hline \multirow{2}{*}{11} & $\mathrm{BN}-11 \mathrm{a}$ & 0,60 & 0,58 & $0,74 *$ & 0,69 & 0,43 & 0,46 & 0,54 & 0,55 & 0,62 & 0,61 \\
\hline & BN-11b & $0,61 *$ & 0,59 & 0,74 & $0,69 *$ & 0,46 & 0,46 & 0,56 & 0,56 & $0,64 *$ & 0,62 \\
\hline 12 & BN-12 & 0,60 & 0,59 & 0,74 & 0,68 & 0,43 & 0,48 & 0,54 & 0,56 & 0,62 & 0,61 \\
\hline 14 & BN-14 & 0,59 & 0,57 & 0,71 & 0,66 & 0,45 & 0,48 & 0,55 & 0,55 & 0,62 & 0,61 \\
\hline \multirow{2}{*}{15} & $\mathrm{BN}-15 \mathrm{a}$ & 0,60 & 0,58 & $\mathbf{0 , 7 3}$ & 0,67 & 0,44 & 0,47 & 0,55 & 0,55 & 0,62 & 0,61 \\
\hline & $\mathrm{BN}-15 \mathrm{~b}$ & 0,60 & 0,58 & 0,71 & 0,66 & 0,46 & 0,48 & 0,56 & 0,56 & 0,62 & 0,60 \\
\hline \multirow{3}{*}{16} & $\mathrm{BN}-16 \mathrm{a}$ & 0,60 & 0,57 & 0,72 & 0,65 & 0,45 & 0,47 & 0,55 & 0,55 & 0,62 & 0,60 \\
\hline & BN-16b & 0,59 & 0,57 & 0,71 & 0,66 & 0,45 & 0,47 & 0,55 & 0,55 & 0,62 & 0,61 \\
\hline & $\mathrm{BN}-16 \mathrm{c}$ & $\mathbf{0 , 6 0}$ & 0,58 & 0,71 & 0,65 & 0,47 & 0,49 & $\mathbf{0 , 6 5}$ & 0,56 & 0,63 & 0,60 \\
\hline
\end{tabular}

* Statistically significant when tested against BN-18 using 95\% LSD ANOVA test $(\mathrm{p}<0.05)$. 
Table 6: Average values for accuracy, sensitivity, specificity, HMSS and ROC area for BN-18 and BN-7 (training and test data).

\begin{tabular}{|c|c|c|c|c|}
\hline \multirow{2}{*}{ Indicators } & \multicolumn{4}{|c|}{ BN results } \\
\cline { 2 - 5 } & \multicolumn{2}{|c|}{ BN-18 } & & \\
\cline { 2 - 5 } & training & test & $\mathbf{0 , 6 1}^{*}$ & $\mathbf{0 , 6 0} *$ \\
\hline Accuracy & 0,59 & 0,58 & $\mathbf{0 , 7 4}^{*}$ & $\mathbf{0 , 7 0}$ \\
\hline Sensitivity & 0,71 & 0,65 & $\mathbf{0 , 4 6}$ & 0,48 \\
\hline Specificity & 0,45 & 0,49 & $\mathbf{0 , 5 7}$ & $\mathbf{0 , 5 7}$ \\
\hline HMSS & 0,55 & 0,56 & $\mathbf{0 , 6 5}^{*}$ & $\mathbf{0 , 6 3}^{*}$ \\
\hline ROC area & 0,62 & 0,61 &
\end{tabular}

* Statistically significant when tested against BN-18 using 95\% LSD ANOVA test $(\mathrm{p}<0.05)$. 
Table 7: Inference results for simple evidences in BN-7

\begin{tabular}{|c|c|c|c|c|}
\hline Variable & Evidence & Prob. KSI & Condition s & satisfied \\
\hline \multirow{7}{*}{ ACT } & AS & 0.3979 & $\mathrm{P}(\mathrm{SEV}=\mathrm{KSI}$ & $A C T=A S)=0.3979$ \\
\hline & $\mathrm{CF}$ & 0.4840 & $P(S E V=K S I$ & $\mathrm{ACT}=\mathrm{CF})=0.4840$ \\
\hline & $\mathrm{HO}$ & 0.5778 & $\mathrm{P}(\mathrm{SEV}=\mathrm{KSI}$ & $\mathrm{ACT}=\mathrm{HO})=0.5778$ \\
\hline & 0 & 0.3965 & $\mathrm{P}(\mathrm{SEV}=\mathrm{KSI}$ & $A C T=O)=0.3965$ \\
\hline & PU & 0.2676 & $\mathrm{P}(\mathrm{SEV}=\mathrm{KSI}$ & $A C T=P U)=0.2676$ \\
\hline & $\mathrm{R}$ & 0.4910 & $\mathrm{P}(\mathrm{SEV}=\mathrm{KSI}$ & $A C T=R)=0.4910$ \\
\hline & SP & 0.2998 & $\mathrm{P}(\mathrm{SEV}=\mathrm{KSI}$ & $A C T=S P)=0.2998$ \\
\hline \multirow{3}{*}{ AGE } & {$[18-25]$} & 0.5034 & $\mathrm{P}(\mathrm{SEV}=\mathrm{KSI}$ & $\mathrm{AGE}=[18-25])=0.5034$ \\
\hline & $(25-64]$ & 0.4233 & $\mathrm{P}(\mathrm{SEV}=\mathrm{KSI}$ & AGE $=(25-64])=0.4233$ \\
\hline & $>64$ & 0.4803 & $P(S E V=K S I$ & $A G E=>64)=0.4803$ \\
\hline \multirow{4}{*}{ ATF } & GW & 0.4653 & $\mathrm{P}(\mathrm{SEV}=\mathrm{KSI}$ & ATF $=G W)=0.4653$ \\
\hline & $\mathrm{HR}$ & 0.3124 & $\mathrm{P}(\mathrm{SEV}=\mathrm{KSI}$ & ATF $=H R)=0.3124$ \\
\hline & LR & 0.3640 & $P(S E V=K S I$ & ATF $=$ LR) $=0.3640$ \\
\hline & 0 & 0.2894 & $\mathrm{P}(\mathrm{SEV}=\mathrm{KSI}$ & ATF=O) $=0.2894$ \\
\hline \multirow{2}{*}{ GEN } & $\mathrm{F}$ & 0.3258 & $\mathrm{P}(\mathrm{SEV}=\mathrm{KSI}$ & $\mathrm{GEN}=\mathrm{F})=0.3258$ \\
\hline & $\mathbf{M}$ & 0.4715 & $\mathrm{P}(\mathrm{SEV}=\mathrm{KSI}$ & $G E N=M)=0.4715$ \\
\hline \multirow{5}{*}{ LIG } & $\mathrm{D}$ & 0.3415 & $\mathrm{P}(\mathrm{SEV}=\mathrm{KSI}$ & $L I G=D)=0.3415$ \\
\hline & $\mathrm{DL}$ & 0.4113 & $\mathrm{P}(\mathrm{SEV}=\mathrm{KSI}$ & $\mathrm{LIG}=\mathrm{DL})=0.4113$ \\
\hline & $I$ & 0.5891 & $\mathrm{P}(\mathrm{SEV}=\mathrm{KSI}$ & LIG=I)=0.5891 \\
\hline & $S$ & 0.4728 & $P(S E V=K S I$ & LIG $=S)=0.4728$ \\
\hline & $\mathrm{W}$ & 0.5508 & $\mathrm{P}(\mathrm{SEV}=\mathrm{KSI}$ & LIG $=W)=0.5508$ \\
\hline \multirow{2}{*}{$\mathrm{NOI}$} & 1 & 0.5104 & $\mathrm{P}(\mathrm{SEV}=\mathrm{KSI}$ & $\mathrm{NOI}=1)=0.5104$ \\
\hline & $>1$ & 0.3000 & $\mathrm{P}(\mathrm{SEV}=\mathrm{KSI}$ & $\mathrm{NOI}=>1)=0.3000$ \\
\hline \multirow{3}{*}{ Ol } & 1 & 0.5100 & $\mathrm{P}(\mathrm{SEV}=\mathrm{KSI}$ & $\mathrm{OI}=1)=0.5100$ \\
\hline & 2 & 0.4250 & $P(S E V=K S I$ & $\mathrm{OI}=2)=0.4250$ \\
\hline & $>2$ & 0.4213 & $\mathrm{P}(\mathrm{SEV}=\mathrm{KSI}$ & $\mathrm{OI}=>2)=0.4213$ \\
\hline
\end{tabular}


Table 8: Inference results for multiple evidences in BN-7

\begin{tabular}{|c|c|c|c|}
\hline \multirow{2}{*}{$\begin{array}{c}\text { No.Var. } \\
1 \\
\end{array}$} & \multicolumn{2}{|c|}{ Condition satisfied } & \multirow{2}{*}{$\begin{array}{l}\text { Prob. KSI } \\
0.5891 \\
\end{array}$} \\
\hline & $P(S E V=K S I$ & LIG=I) & \\
\hline \multirow{7}{*}{2} & $P(S E V=K S I$ & LIG $=I, A C T=A S$ ) & 0.5374 \\
\hline & $P(S E V=K S I$ & $L I G=I, A C T=C F)$ & 0.6225 \\
\hline & $P(S E V=K S I$ & LIG=I, ACT=HO) & 0.7063 \\
\hline & $P(S E V=K S I$ & LIG=I, ACT=O) & 0.5359 \\
\hline & $P(S E V=K S I$ & LIG=I, ACT=PU) & 0.3911 \\
\hline & $P(S E V=K S I$ & LIG $=\mathrm{I}, \mathrm{ACT}=\mathrm{R})$ & 0.6290 \\
\hline & $P(S E V=K S I$ & $L I G=I, A C T=S P$ ) & 0.4294 \\
\hline \multirow{2}{*}{3} & $P(S E V=K S I$ & LIG=I, ACT=HO, NOI=1) & 0.7545 \\
\hline & $P(S E V=K S I$ & $\mathrm{LIG}=\mathrm{I}, \mathrm{ACT}=\mathrm{HO}, \mathrm{NOI}>1$ ) & 0.5582 \\
\hline \multirow{3}{*}{4} & $P(S E V=K S I$ & LIG=I, ACT=HO, NOI=1, OI=1) & 0.5713 \\
\hline & $P(S E V=K S I$ & LIG=I, ACT=HO, NOI=1, OI=2) & 0.6714 \\
\hline & $P(S E V=K S I$ & LIG=I, ACT=HO, NOI=1, OI=>2) & 0.9502 \\
\hline \multirow{3}{*}{5} & $P(S E V=K S I$ & LIG=I, ACT=HO, NOI=1, OI=>2, AGE=[18-25]) & 0.9595 \\
\hline & $\mathrm{P}(\mathrm{SEV}=\mathrm{KSI}$ & LIG=I, ACT=HO, NOI=1, OI=>2, AGE=[25-64)) & 0.9450 \\
\hline & $P(S E V=K S I$ & LIG $=\mathrm{I}, \mathrm{ACT}=\mathrm{HO}, \mathrm{NOI}=1, \mathrm{OI}=>2, \mathrm{AGE}=>64)$ & 0.9558 \\
\hline \multirow{2}{*}{6} & $P(S E V=K S I$ & $\mathrm{LIG}=\mathrm{I}, \mathrm{ACT}=\mathrm{HO}, \mathrm{NOI}=1, \mathrm{OI}=>2, \mathrm{AGE}=[18-25], \mathrm{GEN}=\mathrm{F})$ & 0.9336 \\
\hline & $P(S E V=K S I$ & | LIG=I, ACT=HO, NOI=1, OI=>2, AGE=[18-25], GEN=M) & 0.9629 \\
\hline \multirow{4}{*}{7} & $P(S E V=K S I$ & LIG=I, ACT=HO, NOI=1, OI=>2, AGE=[18-25], GEN=M, ATF=GW) & 0.9651 \\
\hline & $P(S E V=K S I$ & LIG=I, ACT=HO, NOI=1, OI=>2, AGE=[18-25], GEN=M, ATF=HR) & 0.9353 \\
\hline & $\mathrm{P}(\mathrm{SEV}=\mathrm{KSI}$ & LIG=I, ACT=HO, NOI=1, OI=>2, AGE=[18-25], GEN=M, ATF=LR) & 0.9479 \\
\hline & $P(S E V=K S I$ & $\mathrm{LIG}=\mathrm{I}, \mathrm{ACT}=\mathrm{HO}, \mathrm{NOI}=1, \mathrm{OI}=>2, \mathrm{AGE}=[18-25], \mathrm{GEN}=\mathrm{M}, \mathrm{ATF}=\mathrm{O})$ & 0.9283 \\
\hline
\end{tabular}

